\title{
PERBEDAAN HASIL BELAJAR PADA MATA PELAJARAN MATEMATIKA MENGGUNAKAN MODEL TAI DAN MODEL KONVENSIONAL DI SDN DERMO I BANGIL KABUPATEN PASURUAN
}

\author{
Aulia Nur Rahma, Ichsan Anshory AM, Erna Yayuk \\ Program Studi Pendidikan Guru Sekolah Dasar, Fakultas Keguruan dan Ilmu Pendidikan, \\ Universitas Muhammadiyah Malang \\ Email : aulianurrahma70@gmail.com
}

\begin{abstract}
According to observation done by researcher that in SDN Dermo I of Bangil Subdistrict Pasuruan. The research purposes are: (1) finding out and describing student's learning result difference after learning process using cooperative learning model: TAI with conventional learning model in SDN Dermo 1 Elementary School of Bangil Sub-district Pasuruan Regency, and (2) finding out and describing which model are more effective between cooperative model TAI type and conventional model. The research uses experiment research type. Pretest is analyzed with normality and homogenity test, according to the analysis, there found that all classes has normal distribution and homogen. T-test analysis shows that learning result using cooperative learning model TAI type with average 72.50 is significantly better than learning result using conventional learning model with average 62.00.
\end{abstract}

\begin{abstract}
Abstrak: Berdasarkan hasil observasi yang telah dilakukan peneliti bahwa di SDN Dermo I Bangil Kabupaten Pasuruan. Peneliti mencoba menerapkan pembelajaran kooperatif, salah satu pembelajaran kooperatif TAI. Penelitian ini bertujuan untuk mengetahui: (1) untuk mengetahui dan mendeskripsikan perbedaan hasil belajar siswa setelah kegiatan pembelajaran menggunakan model TAI dengan model konvensional di SDN Dermo 1 Bangil Kabupaten Pasuruan, dan (2) Untuk mengetahui dan mendeskripsikan manakah model yang lebih efektif antara model TAI dengan model konvensional. Penelitian ini menggunakan jenis penelitian eksperimen. Hasil pretest dianalisis dengan uji normalitas dan homogenitas, berdasarkan analisis tersebut didapatkan semua kelas berdistribusi normal dan homogen. Hasil analisis uji-t yaitu hasil belajar menggunakan model TAI dengan rata-rata 72,50 lebih baik secara signifikan dibanding dengan hasil belajar menggunakan model konvensional dengan rata-rata 62,00.
\end{abstract}

Kata Kunci: hasil belajar matematik, model TAI, model konvensional

\section{Pendahuluan}

Dalam upaya peningkatan kualitas sumber daya manusia merupakan tugas besar untuk meningkatkan kualitas sumber daya manusia melalui pendidikan yang baik, terarah, dan sarana, prasarana pendidikan dan guru yang berkualitas. Pendidikan merupakan suatu kebutuhan yang sangat penting bagi setiap manusia. Melalui pendidikan setiap orang dapat mengembangkan potensi yang ada pada dirinya untuk meningkatkan kesejahteraan hidupnya. Oleh sebab itu, guru yang berkualitas akan melahirkan pendidikan yang berkualitas dan pada gilirannya akan menghasilkan manusia yang berkualitas (Yamin, dkk. 2009:2).

Dalam kegiatan belajar mengajar akan melibatkan semua komponen pengajaran tersebut (Djamarah, 2010:41). Ketujuh komponen pembelajaran tersebut harus diperhatikan oleh guru dalam memilih dan menentukan model-model pembelajaran apa yang akan digunakan dalam kegiatan pembelajaran. Diharapkan juga, agar guru dapat menciptakan situasi belajar yang nyaman sehingga murid dapat bekerjasama serta mengembangkan wawasannya melalui 
model-model pembelajaran yang diterapkan sehingga guru dapat mengelola kelas dengan efektif.

Dalam kegiatan belajar mengajar terkadang guru masih menggunakan model pembelajaran konvensional, dimana model pembelajaran ini umumnya diarahkan kepada kemampuan anak untuk menerima, mengingat dan menghafal informasi atau pengetahuan dari guru ke siswa. Guru masih dominan menjelaskan dan memberikan tugas, siswa hanya menerima informasi secara pasif (student center) dan belajar individual. Dalam pembelajaran matematika di SDN Dermo I Bangil Kab. Pasuruan masih terdapat permasalahan dimana siswa masih kurang paham konsep dasar dalam pembelajaran matematika, siswa kurang aktif dan bersifat individual dikarenakan kurangnya variasi model pembelajaran yang digunakan. Upaya agar siswa dapat memahami konsep yang sulit akan lebih baik jika siswa saling berdiskusi, dan diharapkan juga guru dapat menerapkan model pembelajaran yang lebih baik.

Dilihat dari kondisi pembelajaran tersebut, terdapat salah satu model pembelajaran yang di dalamnya siswa dapat bekerja sama dan saling membantu adalah model pembelajaran kooperatif dimana pembelajaran ini bernaung dalam teori kontruktivistik, pembelajaran yang lebih memudah menemukan dan memahamkan konsep. Model pembelajaran kooperatif yang didalamnya siswa dapat mengatasi kesulitan belajar secara individual adalah model pembelajaran kooperatif TAI.

Menurut Joyce \& Weil (dalam Trianto 2007:3) Model pembelajaran adalah suatu perencanaan atau pola yang dapat digunakan sebagai pedoman dalam perencanaan pembelajaran di kelas atau pembelajaran dalam tutorial dan menentukan perangkat-perangkat pembelajaran termasuk bukubuku, film, komputer, kurikulum, dan lainlain.
Menurut Sanjaya (2009:242) Pembelajaran kooperatif (cooperative learning) merupakan model pembelajaran dengan menggunakan sistem pengelompokan/tim kecil, yaitu antara empat sampai enam orang yang mempunyai latar belakang kemampuan akademik, jenis kelamin, ras, atau suku yang berbeda (heterogen).

Menurut Slavin (2005:189) Pembelajaran yang menekankan tujuan-tujuan kelompok dan tanggung jawab individual sehingga siswa dapat bekerja dalam tim-tim untuk mengemban tanggung jawab mengelola dan memeriksa secara rutin, saling membantu sama lain dalam menghadapi masalah, dan saling memberi dorongan untuk maju.

Menurut Winataputra (2011:7.1) Model pembelajaran konvensional adalah pembelajaran yang lebih menekankan pada hafalan dan melupakan kehidupan nyata dalam proses pembelajaran. Matematika adaah bahasa simbolis yang memiliki fungsi praktis untuk mengekspresikan hubunganhubungan kuantitatif dan keruangan. Ruang lingkup matematika meliputi pengoperasian perhitungan, pengukuran, aritmatika, kalkulasi, geometri dan aljabar (Delphie, 2009:2).

Menurut Sudjana (2005:22) Hasil belajar adalah kemampuan-kemampuan yang dimiliki siswa setelah ia menerima pengalaman belajarnya. Dalam penelitian ini peneliti menggunakan ranah kognitif untuk mengukur hasil belajar dan untuk mengukur ranah kognitif peneliti menggunakan pretest dan posttest.

Tujuan dari Penelitian ini adalah (1) untuk mengetahui dan mendeskripsikan perbedaan hasil belajar siswa setelah kegiatan pembelajaran menggunakan model pembelajaran kooperatif Teams Assisted Individualization (TAI) dengan model pembelajaran konvensional di SDN Dermo 1 Bangil Kab. Pasuruan, dan (2) Untuk mengetahui dan mendeskripsikan manakah model yang lebih efektif antara model koo- 
peratif tipe Teams Assisted Individualization (TAI) dengan model konvensional.

\section{Metode Penelitian}

Jenis penelitian yang digunakan pada penelitian ini adalah penelitian eksperimen karena dilakukan dengan melakukan manimanipulasi yang bertujuan untuk mengetahui efek suatu perlakuan yaitu perlakuan menggunakan model pembelajaran kooperatif Teams Assisted Individualization (TAI) dan model pembelajaran konvensioanl pada mata pelajaran matematika materi operasi hitung bilangan bulat.

Peneliti menjelaskan rancangan penelitian yang digunakan adalah penelitian eksperimen sebenarnya (Desain Pretest Posttest Control Group). Desain ini terdapat dua kelompok yang dipilih secara random dan diobservasi dua kali yaitu sebelum perlakuan (pre-test) dan sesudah perlakuan (post-test). Desain Penelitian Eksperimen Sebenarnya (True-Experimental Desaigns) : The Pretest-Posttest Control Groups

\begin{tabular}{|c|c|c|c|}
\hline Kelompok & Pretes & $\begin{array}{c}\text { Perlakuan } \\
\text { (Treatmen) }\end{array}$ & Postes \\
\hline Eksperimen & $\mathrm{O}_{1}$ & $\mathrm{X}_{1}$ & $\mathrm{O}_{2}$ \\
\hline Kontrol & $\mathrm{O}_{1}{ }^{\prime}$ & $\mathrm{X}_{2}$ & $\mathrm{O}_{2}{ }^{\prime}$ \\
\hline
\end{tabular}

(Darmadi, 2011: 203)

Keterangan :

$\mathrm{O}_{1} \quad=$ Pre-test (tes awal yang diberikan kepada siswa sebelum diberi perlakuan pembelajaran kooperatif TAI).

$\mathrm{O}_{1}{ }^{\prime} \quad=$ Pre-test (tes awal yang diberikan kepada siswa sebelum diberi perlakuan pembelajaran konvensional).

$\mathrm{X}_{1} \quad=$ Perlakuan yang diberikan (Pembelajaran kooperatif TAI).

$\mathrm{X}_{2}=$ Perlakuan yang diberikan (Pembelajaran konvensional).

$\mathrm{O}_{2} \quad=$ Post-test (tes yang diberikan pada siswa setelah diberi perlakuan pembelajaran kooperatif TAI).
$\mathrm{O}_{2}{ }^{\prime}=$ Post-test (tes yang diberikan pada siswa setelah diberi perlakuan pembelajaran konvensional).

Pada pelaksanaan pembelajaran, mula-mula siswa diberi pre-test kemudian hasilnya dianalisis. Pretest digunakan untuk mengetahui apakah rata-rata nilai kedua kelas berasal dari populasi yang berdistribusi normal dan homogen. Pretest dilakukan sebelum siswa diberi materi operasi hitung bilangan bulat dengan pembelajaran kooperatif TAI dan konvensional. Langkah selanjutnya siswa diberi perlakuan yaitu dengan pemberian materi operasi hitung bilangan bulat dengan perlakuan pembelajaran kooperatif TAI dan konvensional. Setelah diberi perlakuan, siswa diberi post-test. Hasil post-test dianalisis untuk melihat perbedaan hasil belajar dari perlakuan yang telah diberikan.

Dalam penelitian ini pengumpulkan data dilakukan dengan beberapa metode yaitu tes, observasi, dokumentasi dan analisis butir soal yaitu dengan uji coba instrumen, uji validitas instrumen, uji reliabilitas, taraf kesukaran butir soal dan daya pembeda soal. Teknik Analisis Data menggunakan analisis hasil pre-test yaitu uji normalitas dan uji homogenitasn dan untuk analisis hasil post-test yaitu menggunakan uji t-dua pihak dan uji t-satu pihak.

\section{Hasil dan Pembahasan}

Pada proses pembelajaran dengan menggunakan model pembelajaran kooperatif TAI dan model pembelajaran konvensional siswa dibagi dalam kelompokkelompok secara heterogen. Hasil penelitian mengenai perbedaan hasil belajar siswa dengan menggunakan pembelajaran kooperatif TAI dan konvensional terhadap standar kompetensi melakukan operasi hitung bilangan bulat dalam pemecahan masalah pada siswa kelas V-A dan V-B di SDN Dermo I Bangil Kabupaten Pasuruan meliputi tes ha- 
sil belajar yang berupa tes hasil belajar kognitif yaitu nilai pre-test dan post-test, untuk observasi dan dokumentasi digunakan sebagai penunjang hasil penelitian.

Hasil belajar kognitif meliputi nilai pre-test dan post-test siswa kelas V-A dengan perlakuan pembelajaran kooperatif TAI dan kelas V-B dengan perlakuan pembelajaran konvensional pada mata pelajaran matematika diperoleh rata-rata nilai pre-test siswa kelas dengan menggunakan pembelajaran kooperatif TAI yaitu 46,25 dan ratarata nilai pre-test kelas dengan menggunamenggunakan pembelajaran konvensional yaitu 40,75. Berdasarkan hasil uji normalitas diperoleh $\chi_{\text {hitung }}^{2} \chi_{\text {tabel }}^{2}(\alpha=0,05)$ baik kelas dengan pembelajaran kooperatif TAI maupun kelas dengan pembelajaran konvensioanl sampel berasal dari populasi yang berdistribusi normal. Hasil analisis uji homogenitas diperoleh $F_{\text {hitung }}<F_{\text {tabel }}(\alpha=0,05)$ baik kelas dengan pembelajaran kooperatif TAI maupun kelas dengan pembelajaran konvensional sampel adalah homogen.

Penerapan model pembelajaran kooperatif TAI pada proses belajar mengajar diperoleh rata rata nilai post-test $=72,50$ sedangkan penerapan model pembelajaran konvensional pada proses belajar mengajar diperoleh rata rata nilai post-test $=62,00$. Dari analisis hasil penelitian didapatkan bahwa terdapat perbedaan hasil belajar dengan menggunakan model pembelajaran kooperatif TAI dan hasil belajar dengan menggunakan pembelajaran konvensional pada mata pelajaran matematika yang ditandai dengan perhitungan uji hipotesis yang menggunakan uji $\mathrm{t}$ dua pihak. Uji $\mathrm{t}$ dua pihak ini digunakan untuk mengetahui rata-rata hasil belajar siswa antara dua kelas tersebut apakah sama atau berbeda. Hasil uji $t$ dua pihak yang diperoleh yaitu terdapat perbedaan rata-rata hasil belajar siswa antara kelas dengan pembelajaran kooperatif TAI dan kelas dengan pembelajaran konvensional.
Pada uji-t pihak kanan digunakan untuk mengetahui apakah rata-rata hasil belajar siswa antara kelas dengan model pembelajaran kooperatif TAI lebih baik dibandingkan dengan rata-rata hasil belajar siswa kelas konvensioanl ataukah rata-rata hasil belajar siswa antara dua kelas tersebut sama. Pada penelitian ini hasil uji-t satu pihak diperoleh yaitu rata-rata hasil belajar siswa antara kelas dengan pembelajaran kooperatif TAI lebih baik dibandingkan dengan rata-rata hasil belajar siswa kelas dengan pembelajaran konvensional.

Berdasarkan hasil belajar pre-test dan post-test, dapat dilihat rata-rata hasil belajar siswa pada masing-masing kelas. Dalam grafik berikut digambarkan nilai rata-rata pre-test dan post-test dari kelas V-A dan VB. Untuk nilai rata-rata pre-test ditunjukkan oleh grafik warna biru dan nilai rata-rata post-test ditunjukkan oleh grafik warna merah.

Nilai rata-rata pre-test dan post-test

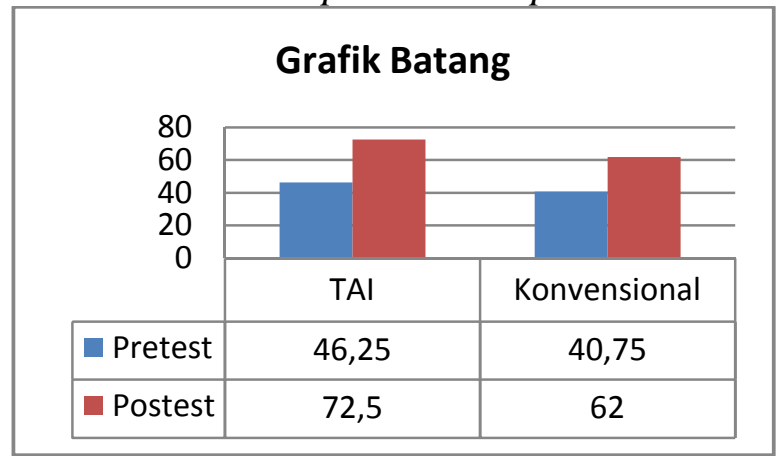

Hal ini membuktikan bahwa model pembelajaran kooperatif TAI efektif dikarenakan dalam model pembelajaran kooperatif TAI guru tidak lagi berperan aktif melainkan siswa yang berperan aktif (student center), dalam pembelajaran kooperatif TAI guru berperan sebagai fasilitor, berbeda dengan pembelajaran konvensional dimana pembelajaran berpusat pada guru dan pada saat berkelompok dalam penyelesaian tugas sering diborong oleh salah seorang anggota kelompok.

Berbeda dengan pembelajaran kooperatif TAI, dimana seluruh anggota kelom- 
pok dituntut untuk paham dan mengerti, karena hasil belajar siswa secara individual dibawa kedalam kelompok-kelompok untuk didiskusikan dan saling dibahas oleh anggota kelompok, dan dalam setiap kelompok terdapat seorang siswa yang lebih mampu yang bertugas membantu secara individual siswa lain yang kurang mampu. Nantinya anggota kelompok bertanggung jawab atas keseluruhan jawaban sebagai tanggung jawab bersama. Model pembelajaran kooperatif TAI ini, lebih menekankan pada tujuan-tujuan kelompok dan tanggung jawab individual (Slavin, 2005:191).

Berbeda dengan model konvensional dimana didalam model ini guru lebih dominan menjelaskan dan memberikan tugas, guru lebih menekankan pada hafalan dan melupakan kehidupan nyata dalam proses pembelajarannya. Winataputra (2011:7.1).

\section{Simpulan}

Hasil analisis uji-t dua pihak dinyatakan bahwa ada perbedaan hasil belajar menggunakan model pembelajaran kooperatif TAI dan model pembelajaran konvensioanl di SDN Dermo I Bangil Kabupaten Pasuruan dan dapat dilihat dari rata rata nilai post-test kelas TAI yaitu 72,50 dan rata-rata nilai post-test kelas konvensional yaitu 62,00 .

Dari hasil analisis uji-t pihak kanan yang digunakan untuk mengetahui apakah rata-rata hasil belajar siswa antara kelas dengan model pembelajaran kooperatif TAI lebih baik dibandingkan dengan rata-rata hasil belajar siswa kelas konvensioanl. Pada hasil analisis uji-t pihak kanan dinyatakan bahwa hasil belajar siswa menggunakan model pembelajaran kooperatif TAI lebih baik dibandingkan dengan hasil belajar siswa menggunakan model pembelajaran konvensional pada mata pelajaran matematika standar kompetensi melakukan operasi hitung bilangan bulat dalam pemecahan ma- salah pada siswa kelas V-A dan V-B di SDN Dermo I Bangil Kabupaten Pasuruan.

\section{Daftar Rujukan}

Arikunto, Suharsimi. 2013. Dasar-dasar Evaluasi Pendidikan. Jakarta: Bumi Aksara

Darmadi, Hamid. 2011. Metode Penelitian Pendidikan. Bandung: Alfabeta

Delphie, Bandi. 2009. Matematika untuk Anak Berkebutuhan Khusus. Sleman: PT Intan Sejati Klaten

Djamarah, Syaiful Bahri, dkk. 2010. Strategi Belajar Mengajar. Jakarta: Rineka Cipta.

Hadis, Abdul.2008. Psikologi dalam Pendidikan. Bandung: Alfabeta

Hanafiah, Nanang, dkk. 2009. Konsep Strategi Pembelajaran. Bandung: PT Refi ka Aditama

Nababan, G Lian Y. 2011. Perbedaan Hasil Belajar Siswa Dengan Menggunakan Model Konvensional dan Model Pembelajaran Kooperatif Tipe STAD Pada Materi Biosfer Kelas Xi IPS SMA Negeri 1 Pancur Batu. Jurnal Ilmu Pendidikan. 2011:1-13

Nugroho, Siswo, dkk. 2013. Pengaruh Pembelajaran Kooperatif TAI Terhadap Prestasi Belajar Matematika Ditinjau Dari Motivasi Berprestasi Siswa Kelas V Sd Tunas Daud. Jurnal Program Studi Pendidikan Dasar. 3/13

Nurdjannah, Nadhiro. 2011. Perbedaan Hasil Belajar Menggunakan Model Pembelajaran Kooperatif Student Teams Achievement Divisions (STAD) dengan Teams Assisted Indivualization (TAI) di SMK Negeri 1 Beji Kabupaten Pasuruan. Disertai tidak diterbitkan. Surabaya: PT Unesa

Prayitno, Duwi. 2009. 5 jam Belajar Olah Data dengan SPSS 17. Yogyakarta: CV. Andi Offset. 
Riduwan. 2004. Belajar Mudah Penelitian untuk Guru Karyawan dan Peneliti Pemula. Bandung: Alfabeta

Rusman. 2010. Model-model Pembelajaran Mengembangkan Profesionalisme Guru. Jakarta: PT Rajagrafindo Persada

Sanjaya, Wina. 2009. Strategi Pembelajaran Berorientasi Standar Proses Pendidikan. Jakarta: Prenada Media Grup

Slavin, Robert E. Cooperative Learning Teori, Riset dan Praktik. Terjemahan Narulita Yusron. 2005. Bandung: Nusa Media.

Solihatin, Etin, dkk. 2008. Cooperative Learning Analisis Model Pembelajaran IPS. Jakarta: PT Bumi Aksara.

Sudjana, Nana. 2005. Penilaian Hasil Proses Belajar Mengajar. Bandung: PT Remaja Rosdakarya.

Sugiyono. 2010. Statistika untuk Penelitian. Bandung: Alfabeta

Syah, Muhibbin. 2003. Psikologi Belajar. Jakarta: PT RajaGrafindo Persada.

Trianto. 2007. Model Pembelajaran Terpadu dalam Teori dan Praktek. Jakarta: Prestasi Pustaka.

Trianto. 2009. Mendesain Model Pembelajaran Inovatif-Progresif. Jakarta: Prenada Media Group.

Widyantini. 2006. Model Pembelajaran Matematika dengan Pendekatan Kooperatif. (Sri Wardhani, Ed.). Yogyakarta: PPPG Departemen Pendidikan Nasional Pusat Pengembangan dan Penataran Guru Matematika

Winataputra, Udin S., 2011. Materi dan Pembelajaran IPS SD. Jakarta: Universitas Terbuka

Yamin, Martinis, dkk. 2009. Taktik Mengembangkan Kemampuan Individual Siswa. Jakarta: Gaung Persada Press. 